\title{
Evaluasi pemeliharaan taman pada kawasan Bali tropic resort and spa Kabupaten Badung
}

\author{
Ida Ayu Modasih Istacahyani ${ }^{1}$, Cokorda Gede Alit Semarajaya ${ }^{1 *}$, Ni Luh Made Pradnyawathi \\ 1. Prodi Arsitektur Pertamanan, Fakultas Pertanian, Universitas Udayana, Indonesia \\ 2. Prodi Agroekoteknologi, Fakultas Pertanian, Universitas Udayana, Indonesia \\ ${ }^{\star} E$-mail : coksemarajaya@unud.ac.id
}

\begin{abstract}
Evaluation of garden maintenance in Bali tropic resort and spa area of Badung Regency. Maintenance of the park in the area of Bali Tropic Resort and Spa has been gone on since 27 years, so it is interesting to know the efforts that have been done and how the visitors response to the maintenance of the park in the area resort. The purpose of this research is to identify and to evaluate system the maintenance of the park at the Bali Tropic Resort and Spa area. The research method used is survey method. The data collected in this research are primary data and secondary data. Data collection techniques used are observation technique, interview technique, literature study and questionnaire. Interviews were conducted with related parties and questionnaires distributed to 30 respondents with the criteria of using English well. Maintenance system which implemented is a maintenance unit and specialized maintenance system. The results of the evaluation of the maintenance of the park has been well viewed from the cleanliness of the park, the park security, the beauty of the park, cleanliness of fish, cleanliness of planter box, and pavement cleanliness. Suggestions given are written standard of maintenance, maintenance schedule, monitoring card, a reward system in the form of charter and achievement allowance for garden staff to improve work motivation and work discipline so it also can improve the effectiveness and efficiency of work and training that can increase knowledge and skills in maintenance activities for the employee.
\end{abstract}

Keywords: Bali tropic resort and spa, garden evaluation, garden maintenance, maintenance system

\section{Pendahuluan}

Resort adalah sebuah tempat menginap di mana mempunyai fasilitas khusus untuk kegiatan bersantai dan berolahraga seperti tenis, golf, spa, tracking, dan jogging. Resort sebaiknya mempunyai lahan yang ada kaitannya dengan objek wisata, oleh sebab itu sebuah resort berada pada kawasan perbukitan, pegunungan, lembah dan pinggiran pantai. Resort memiliki karakteristik seperti fasilitas pokok seperti ruang tidur dan fasilitas rekreasi outdoor meliputi fasilitas olahraga, kolam renang dan penataan taman (Pendit, 1999 dalam Pudya, 2000). Terciptanya nilai estetis dari suatu taman memerlukan pemeliharaan intensif. Pemeliharaan taman dimaksud untuk menjaga dan merawat areal taman dengan segala fasilitas yang ada di dalamnya agar sedapat mungkin memepertahankan keadaan semula (Sternloff dan Warren, 1984).

Pemilihan tanaman yang diterapkan pada masing-masing bangunan di Bali Tropic Resort and Spa disesuaikan dengan nama-nama tanaman buah seperti, bangunan jeruk bali dipilih tanaman jeruk bali sebagai representasi nama bangunan agar taman-taman tersebut mempunyai ciri masing-masing, selain itu terdapat berbagai macam elemen lunak seperti tanaman melati jepang (Pseudeanthemum reticulatum), pandan bali (Cordyline australis), adam hawa (Rhoeo discolor), pisang-pisangan (Heliconia colinsiana), delima hitam (Punica granatum), rambutan (Nephelium Lappaceum L), mangga (Mangifera indica). Selain tanaman hias dan tanaman buah taman ini juga didukung dengan adanya elemen keras seperti kolam ikan, lampu taman, jalan setapak dan planter box. Pemeliharaan taman pada kawasan Bali Tropic Resort and Spa sudah berlangsung semenjak 27 tahun, sehingga sangat menarik untuk diketahui upaya yang telah dilakukan dan bagaimana tanggapan pengunjung terhadap pemeliharaan taman pada kawasan Bali Tropic Resort and Spa tersebut.

Rumusan Masalah pada penelitian ini yaitu bagaimana sistem pemeliharaan taman pada kawasan Bali Tropic Resort and Spa, Kabupaten Badung serta, bagaimana hasil evaluasi pemeliharaan taman pada kawasan Bali Tropic Resort and Spa, Kabupaten Badung. Tujuan dari penelitian ini adalah mengidentifikasi sistem pemeliharaan taman pada kawasan Bali Tropic Resort and Spa, Kabupaten Badung dan mengevaluasi pemeliharaan taman pada kawasan Bali Tropic Resort and Spa, Kabupaten Badung. 


\section{Metode Penelitian}

\subsection{Lokasi dan Waktu Penelitian}

Kegiatan penelitian dilaksanakan di Bali Tropic Resort and Spa yang terletak di Jalan Pratama 34A, Kecamatan Kuta Selatan, Kabupaten Badung, Provinsi Bali (Gambar 1). Memiliki lokasi seluas tiga hektar dengan iklim tropis dan suhu rata-rata $27,4^{\circ} \mathrm{C}$ yang berbatasan langsung dengan Pantai Nusa Dua dan Pantai Tanjung Benoa dengan menggunakan perpaduan konsep bangunan arsitektur Bali dan arsitektur modern dan menggunakan konsep taman tropis. Penelitian berlangsung dari Bulan Oktober 2016 hingga Bulan Juni 2017.

\subsection{Alat Penelitian}

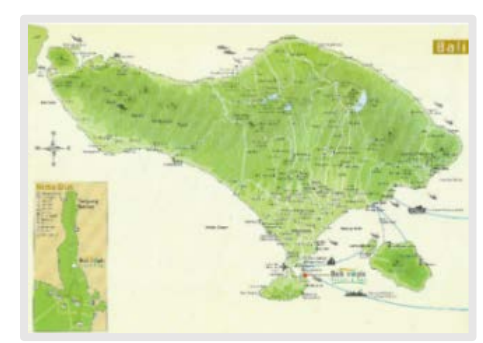

(a) Pulau Bali

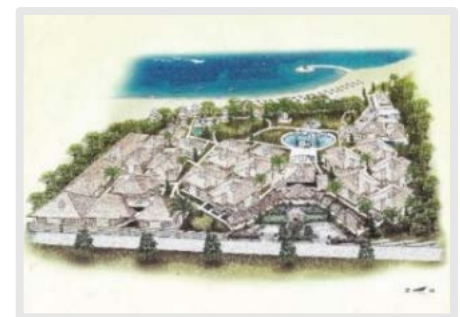

(b) Bali Tropic Resort and Spa

Gambar. 1 Lokasi Penelitian

Alat yang digunakan dalam penelitian ini adalah handphone sebagai pengganti kamera, flashdisk, serta perangkat komputer untuk mengelola data berupa Adobe Photoshop CS6 dan Microsoft Office.

\section{$2.3 \quad$ Metode}

Metode penelitian yang digunakan dalam penelitian ini adalah metode survei. Data yang diperoleh berupa data primer yaitu observasi, wawancara, dan kuisioner, sedangkan data sekunder berasal dari studi pustaka. Wawancara dilakukan dengan pihak terkait yaitu human resources manager, housekeeping managaer, dan supervisor gardener, sedangkan kuisioner ditujukan kepada 30 pengunjung resort untuk mengetahui persepsi pengunjung mengenai kondisi fisik taman. Data yang diperoleh akan ditabulasi dengan menggunakan skala Likert untuk mencari persentase dan kemudian data dianalisis dan dikonversikan kedalam diagram serta diuraikan secara deskriptif untuk memberikan gambaran umum lokasi yang diteliti, sehingga dapat menghasilkan kesimpulan berdasarkan tujuan yang telah dirumuskan.

\subsection{Batasan Penelitian}

Penelitian ini dibatasi pada aspek evaluasi terhadap pemeliharaan taman pada kawasan Bali Tropic Resort and Spa.

\section{Hasil dan Pembahasan \\ 3.1 Gambaran umum \\ 3.1.1 Sejarah Bali Tropic Resort \& Spa}

Bali Tropic Resort and Spa diresmikan pada tanggal 2 April 1990 oleh Bapak Suharto selaku Presiden Republik Indonesia. Lokasi yang memiliki luas areal tiga hektar ini dibeli oleh Bapak Jero Gede Karang T. Suarshana. Hotel tersebut dinamakan Bali Tropic Cottage yang memiliki 96 kamar standar, enam kamar suite, dan satu kamar deluxe suite, coffee shop, satu main dining room, tiga bar dan lobby. Soft opening dilakukan pada Bulan Oktober 1989. Bali Tropic Cottages beberapa kali mengalami perubahan nama dan pada akhirya pada Bulan Agustus 2001 resmi berganti nama menjadi Bali Tropic Resort and Spa.

\subsubsection{Visi dan Misi Bali Tropic Resort \& Spa}

Visi dari Bali Tropic Resort \& Spa menjadi jiwa nyata resort berbudaya bali dengan selera internasional. Misi Bali Tropic Resort and Spa, yaitu

1. Meningkatkan mutu pelayanan dan ketrampilan karyawan menjadi lebih profesional dan efektif sehingga memenuhi kebutuhan dan harapan setiap tamu.

2. Meningkatkan kualitas produk dan fasilitas untuk mengarah menjadi sebuah Boutique Hotel di mana kenyamanan tinggal yang modern disediakan dengan perpaduan konservasi budaya Bali.

3. Meningkatkan loyalitas tamu, menjadikan mereka pelanggan, meningkatkan kesadaran pasar dan memperluas jaringan pemasaran untuk mencapai pendapatan yang maksimum supaya membawa keuntungan bagi pemilik Hotel dan meningkatkan kesejahteraan seluruh karyawan. 


\subsubsection{Struktur Organisasi}

Pemeliharaan taman pada kawasan Bali Tropic Resort and Spa dipimpin oleh excecutive housekeeping di bawah naungan general manager dan diawasi langsung oleh supervisor gardener yang membawahi empat senior gardener, delapan gardener di bawah garis koordinasi dari supervisor housekeeping. Pemeliharaan taman dilaksanakan secara mandiri (Gambar 2).

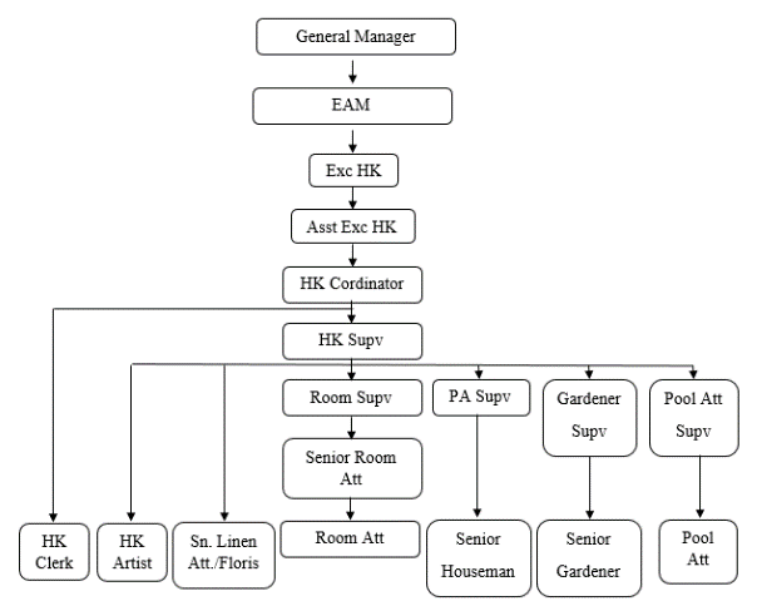

Gambar 2. Struktur Organisasi Bali Tropic Resort and Spa

\subsubsection{Letak dan Luas}

Bali Tropic Resort and Spa terletak di Jalan Pratama 34 A, Kecamatan Kuta Selatan, Kabupaten Badung, Provinsi Bali dengan luas areal tiga hektar. Berbatasan dengan Pantai Tanjung Benoa, batas sebelah timur adalah Selat Nusa Penida atau Pantai Nusa Penida, sebelah selatan berbatasan dengan Desa Adat Tengkulah dan sebelah barat berbatasan dengan Pantai Barat Tanjung Benoa.

\subsubsection{Hidrologi}

Sumber air yang digunakan untuk kepentingan taman adalah air PDAM dan air hasil daur ulang limbah resort yang ditampung dan didaur ulang di lagoon Nusa Dua. Sejumlah keran diletakkan tersebar di areal taman untuk mempermudahkan melakukan kegiatan penyiraman tanaman dan pemebersihan areal outdoor.

\subsection{Hasil dan Pembahasan}

\subsubsection{Hasil Evaluasi Pemeliharaan Taman}

Evaluasi pemeliharaan taman ini bertujuan untuk melihat kinerja dari pihak pengelola pemeliharaan taman pada kawasan Bali Tropic Resort and Spa, serta merupakan tahap yang sangat penting dan sangat menentukan apakah tujuan dari pemeliharaan tercapai atau tidak dan diharapkan dapat dilakukan perbaikan bila ada kekurangan serta diharapkan dapat meningkatkan kinerja pemeliharaan. Hasil dari tabulasi data kuisioner didapat karakteristik dan persepsi responden mengenai kondisi fisik taman pada kawasan tersebut. Karakteristik yang diamati dalam penelitian ini terdiri dari jenis kelamin, negara asal dan profesi. Adapun karakteristik responden dapat dilihat pada Gambar 3 berikut.

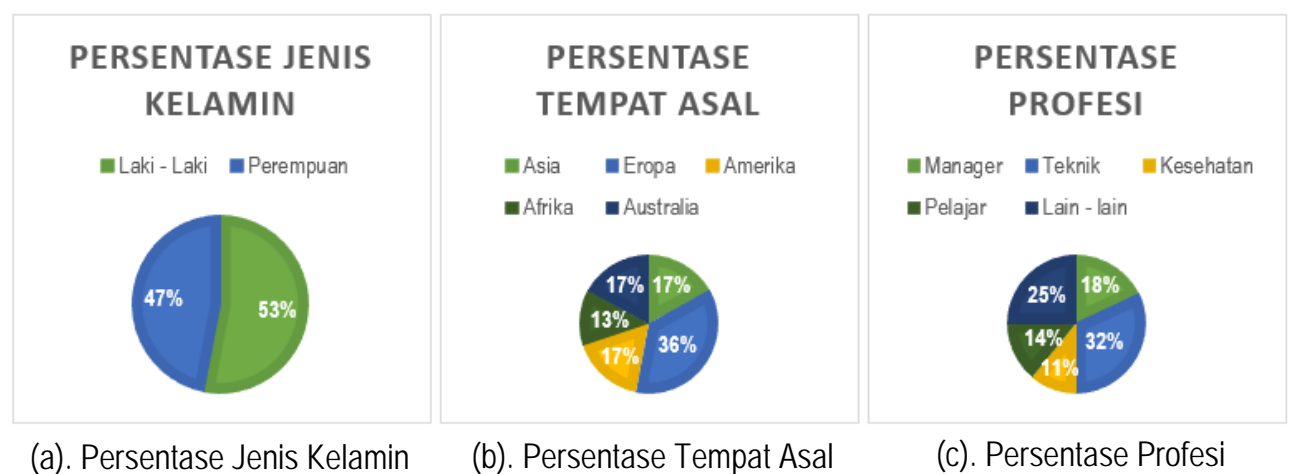

Gambar. 3 Karakteristik Responden 
Persepsi pengunjung sangat dibutuhkan sebagai salah satu unsur penikmat dalam pemeliharaan taman, sehingga ada kesamaan persepsi dalam pengembangannya. Persepsi responden yang diamati dalam penelitian ini terkait kondisi fisik pemeliharaan taman pada kawasan Bali Tropic Resort and Spa seperti kebersihan, keamanan, keindahan kebersihan kolam ikan, planter box dan perkerasan/jalan setapak. Adapun hasil tabulasi data mengenai tanggapan responden terhadap kondisi fisik pemeliharaan taman pada kawasan Bali Tropic Resort and Spa, dapat dilihat pada Gambar 4 sebagai berikut.

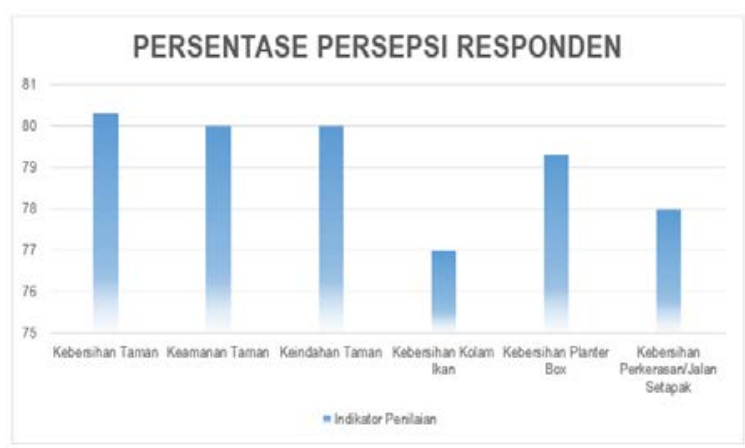

Gambar 4. Persentase Persepsi Responden

Hasil persepsi pengunjung mengenai kondisi fisik taman pada kawasan Bali Tropic Resort and Spa mengenai kebersihan taman, kamanan taman, dan keindahan taman mendapat persepsi sangat baik sedangkan untuk kebersihan kolam ikan, planter box dan jalan setapak/perkerasan mendapat persepsi baik. Pemeliharaan yang dilakukan pihak pengelola sudah baik dan didukung oleh adanya frekuensi pemeliharaan yang intensif serta kapasitas tenaga kerja yang di miliki oleh Bali Tropic Resort and Spa.

\subsubsection{Sistem Pemeliharaan Taman}

Pemeliharaan taman pada Bali Tropic Resort and Spa dilakukan secara mandiri. Sistem yang diterapkan adalah sistem pemeliharaan unit dan karyawan pemeliharaan khusus.

\subsubsection{Konsep Pemeliharaan Taman}

Bentuk pemeliharaan taman yang diterapkan pada kawasan Bali Tropic Resort and Spa adalah pemeliharaan ideal dan pemeliharaan fisik. Pemeliharaan ideal yang dilakukan mengacu pada desain dan tujuan awal untuk mempertahakan konsep bangunan perpaduan khas Bali dan arsitektur modern dengan menggunakan konsep taman tropis, sedangkan pemeliharaan fisik dilakukan untuk menunjang pemeliharaan ideal meliputi pekerjaan penyapuan, pengangkutan sampah, pemeliharaan ornamen taman, pemangkasan rumput, semak, perdu dan pohon, pemupukan, pengendalian hama dan penyakit, penyiraman, pendangiran dan penyiangan gulma, serta perbanyakan tanaman.

\subsubsection{Ketenagakerjaan}

Staf gardener bekerja sesuai shift yang sudah ditentukan oleh supervisor gardener. Shift pagi mulai pukul 06.00 WITA hingga pukul 14.00 WITA, shift siang dibagi menjadi dua yaitu mulai pukul 12.00 WITA hingga pukul 20.00 WITA dan mulai pukul 13.00 WITA hingga pukul 21.00 WITA. Seluruh staf gardener, bekerja maksimum tujuh jam kerja tiap harinya. Kapasitas kerja staf gardener di Bali Tropic Resort and Spa diperoleh berdasarkan hasil pengamatan dan wawancara yang dilakukan di lapang, kemudian dibandingkan dengan kapasitas kerja berdasarkan teori Arifin dan Arifin (2005). Kapasitas tenaga kerja pemeliharaan taman dapat dilihat pada Tabel 1 berikut:

Tabel 1. Kapasitas Tenaga Kerja Pemeliharaan

\begin{tabular}{|c|c|c|c|c|c|c|}
\hline \multirow{2}{*}{$\begin{array}{c}\text { Jenis pekerjaan } \\
\text { pemeliharaan }\end{array}$} & \multirow{2}{*}{ Satuan } & \multicolumn{2}{|c|}{ Kapasitas kerja $\left(\mathrm{m}^{2} / \mathrm{jam}\right)$} & \multicolumn{2}{|c|}{ Frekuensi pemeliharaan } & \multirow{2}{*}{$\begin{array}{c}\text { Efektivitas kerja } \\
\text { per jam (\%) }\end{array}$} \\
\hline & & (a) & (b) & (a) & (b) & \\
\hline 1 Penyapuan & $\mathrm{m}^{2}$ & 680 & 800 & Harian & Harian & 85 \\
\hline 2 Pemangkasan rumput & $\mathrm{m}^{2}$ & 350 & 250 & Bulanan & Bulanan & 140 \\
\hline 3 Pemangkasan semak & $\mathrm{m}^{2}$ & 10 & 10 & Bulanan & Bulanan & 100 \\
\hline 4 Penyiraman & $\mathrm{m}^{2}$ & 180 & 150 & Harian & Harian & 120 \\
\hline 5 Pemupukan & $m^{2}$ & 95 & 100 & 3 Bulanan & 3 Bulanan & 95 \\
\hline $6 \begin{array}{l}\text { Penyiangan Gulma dan } \\
\text { Pendangiran }\end{array}$ & $m^{2}$ & 40 & 40 & Bulanan & Bulanan & 100 \\
\hline \multicolumn{6}{|c|}{ Rata - rata } & 107 \\
\hline
\end{tabular}

Keterangan: $\quad$ (a) Pengamatan Lapangan, (b). Arifin dan Arifin (2005) 
Berdasarkan perhitungan dari hasil perbandingan pengamatan kapasitas kerja staf gardener di Bali Tropic Resort and Spa, terdapat bebrapa jenis pekerjaan pemeliharaan yang kurang dari standar yaitu penyapuan, dan pemupukan (di bawah 100\%) serta ada beberapa jenis pekerjaan pemeliharaan yang melebihi standar acuan yaitu pemangkasan, dan penyiraman (di atas 100\%). Permasalahan tersebut dapat disebabkan karena beristirahat bukan pada jam istirahat, kerusakan alat pada saat pemakaian, dan perbedaan kondisi lapang, seperti topografi tapak dan tingkat keragaman vegetasi. Selain itu terdapat pula faktor keterampilan personel, pengalaman kerja staf Bali Tropic Resort and Spa yang lebih lama memungkinkan kapasitas kerja yang lebih tinggi pada kegiatan tertentu. Permasalahan tersebut dapat diatasi dengan meningkatkan pengawasan oleh supervisior gardener serta melakukan pengecekan alat dan pemeliharaan rutin alat agar tidak ada masalah pada saat pekerjaan pemeliharaan, selain itu perlu adanya pelatihan untuk seorang supervision gardener agar dapat memimpin staf gardener dengan baik (Carpenter et al., 1975).

Perhitungan jumlah tenaga kerja yang dibutuhkan dihitung berdasarkan luas wilayah dan jenis pekerjaan yang dilakukan. Perhitungan kebutuhan hari orang kerja (HOK) untuk pemeliharaan taman pada kawasan Bali Tropic Resort and Spa dalam satu tahun dapat dilihat pada Tabel 2 berikut :

Tabel 2. Kebutuhan HOK Pemeliharaan Taman Bali Tropic Resort and Spa

\begin{tabular}{|c|c|c|c|c|c|c|c|}
\hline $\begin{array}{l}\text { Jenis pekerjaan } \\
\text { pemeliharaan }\end{array}$ & $\begin{array}{c}\mathrm{KK}^{1} \\
\left(\mathrm{~m}^{2} \text { ljam }\right)\end{array}$ & $\begin{array}{l}\text { Luas area } \\
\qquad\left(\mathrm{m}^{2}\right)\end{array}$ & $\begin{array}{l}\text { Kebutuhan } \\
\text { waktu (jam) }\end{array}$ & $\begin{array}{l}\text { HOK per } \\
\text { kegiatan }^{2}\end{array}$ & $\begin{array}{l}\text { Frekuensi per } \\
\text { tahun }^{3}\end{array}$ & HOK 1 tahun & $\mathrm{KTK}^{4}$ \\
\hline 1 Penyapuan & 680 & 11.958 & 17,59 & 2,51 & 365 & 916,15 & 4 \\
\hline 2 Pemangkasan rumput & 350 & 1.583 & 4,52 & 0,65 & 12 & 7,75 & 1 \\
\hline 3 Pemangkasan semak & 10 & 280 & 28,00 & 4,00 & 12 & 48,00 & 1 \\
\hline 4 Penyiraman & 180 & 9.854 & 54,74 & 7,82 & 365 & $2.854,53$ & 6 \\
\hline 5 Pemupukan & 95 & 240 & 2,53 & 0,36 & 4 & 1,44 & 1 \\
\hline \multirow[t]{2}{*}{$6 \begin{array}{l}\text { Penyiangan Gulma dan } \\
\text { Pendangiran }\end{array}$} & 40 & 240 & 6,00 & 0,86 & 12 & 10,32 & 1 \\
\hline & & Total & & & & $3.838,20$ & 14 \\
\hline
\end{tabular}

Keterangan : ${ }^{1}$ kapasitas kerja berdasarkan pengamatan di lapangan, ${ }^{2 h a r i ~ o r a n g ~ k e r j a, ~ d e n g a n ~ k e t e n t u a n ~}$ tujuh jam kerja, ${ }^{3}$ Perhitungan total 365 hari kerja selama satu tahun (tujuh hari/minggu), ${ }^{4}$ kebutuhan tenaga kerja

Hasil perhitungan HOK menunjukkan bahwa kegiatan pemeliharaan taman pada kawasan Bali Tropic Resort and Spa masih kekurangan sedikit tenaga kerja. Tenaga kerja yang diperlukan seharusnya 14 orang, sedangkan tenaga kerja yang dimiliki hanya 13 orang. Pemeliharaan taman pada Tabel 2 di atas membuktikan bahwa pekerjaan pemeliharaan taman sudah efektif dan efisien, tetapi kaperluan tenaga kerja tersebut belum mencakup kegiatan yang bersifat khusus seperti pembersihan kolam ikan, perbanyakan tanaman dan pemangkasan pohon. Penambahan tenaga kerja mungkin dapat diprioritaskan untuk jenis pekerjaan dengan kapasitas kerja di bawah standar seperti penyapuan rumput dan pemupukan.

Pembagian pekerjaan juga harus diimbangi dengan hak para tenaga kerja sesuai dengan perjanjian. Penghasilan dan tunjangan untuk staf yang sudah resmi dikontrak diberikan sesuai dengan UMR Kabupaten Badung ditambah dengan uang service, sedangkan untuk pekerja harian hanya mendapatkan penghasilan dan mendapat fasilitas makan siang.

\subsubsection{Administrasi}

Komunikasi antar manager, supervisor dan gardener berjalan baik melalui briefing yang dilaksanakan setiap Hari Selasa dan Kamis. Keluhan, masukan dan kekurangan dalam pelaksanaan pemeliharaan dapat tersampaikan secara langsung. Wilayah kerja dibagi menjadi beberapa unit yang dikerjakan langsung oleh satu staf gardener dan semua pekerjaan pemeliharaan taman diawasi langsung oleh supervisor (Gambar 5). Ketesediaan alat dan bahan merupakan faktor yang mempengaruhi kelancaraan pelaksanaan pemeliharaan. Pemesanan dilakukan dengan dua cara yaitu direct order (DO) dan purchase request (PR). Pekerjaan pemeliharaan taman pada kawasan Bali Tropic Resort \& Spa sangat fleksibel. Kondisi taman diupayakan terpelihara dengan baik, cara dan waktu pelaksanaan dapat dilakukan sesuai dengan keinginan gardener. Kapasitas kerja menentukan efektivitas kerja dan efisiensi biaya pemeliharaan taman (Arifin dan Arifin, 2005). 


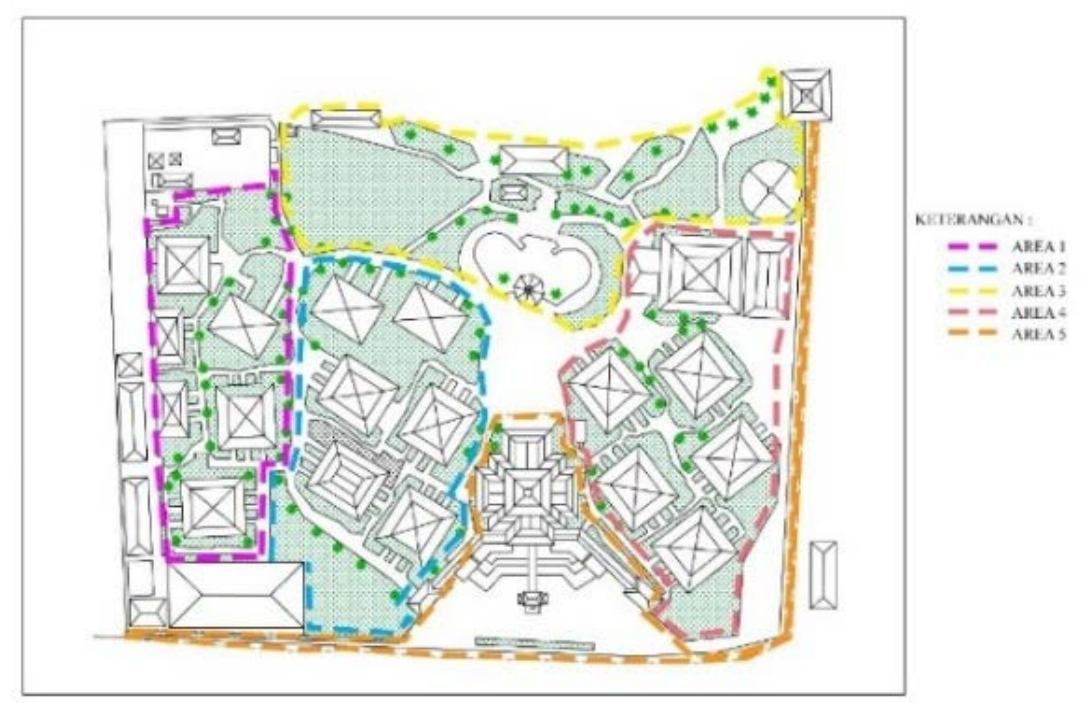

Gambar 5. Pembagian Area Kerja

\subsubsection{Pemeliharaan Fisik Taman Bali Tropic Resort \& Spa}

Pemeliharaan taman pada kawasan Bali Tropic Resort and Spa dibagi menjadi dua yaitu pemeliharaan ideal yang bertujuan untuk memelihara elemen-elemen taman yang ada seperti penyediaan stok tanaman, tempat sampah, lampu penerangan, jaringan utilitas, dan jalan setapak. Jenis pekerjaan pemeliharaan fisik yaitu penyapuan, pengangkutan sampah, pembersihan ornamen taman, penyiraman, pemangkasan, pemupukan, penyiangan gulma serta pengendalian hama dan penyakit.

Kegiatan penyapuan dilakukan untuk menjaga kebersihan areal taman dari sampah baik sampah organik (daun-daun yang berguguran dari pohon, ranting pohon, maupun dari hasil pemangkasan rumput dan pembersihan gulma) maupun sampah anorganik (sampah-sampah plastik). Penyapuan area taman dilakukan setiap dua kali sehari pagi hari dan siang hari (Tabel 1).

Pengangkutan sampah dilakukan untuk mengangkut sampah hasil kegiatan pemeliharaan serta sampah yang berasal dari kamar resort, dan sampah restoran di Bali Tropic Resort and Spa. Pengangkutan sampah dari tempat pembuangan sampah sementara ke tempat pembuangan sampah akhir dilakukan tiga kali dalam satu minggu. Pemeliharaan kolam meliputi pembersihan daun kering, pengurasan dan pemberian pakan ikan (Gambar 6). Selain itu, staf gardener dituntut untuk merawat mesin pompa yang terdapat pada kolam ikan, untuk menghindari ketergantungan terhadap staf engineering. Pembersihan daun kering dan pemberian pakan ikan dilakukan setiap hari pagi dan siang hari, sedangkan untuk pengurasan kolam biasanya dilakukan setiap dua minggu sekali pada masing-masing kolam ikan. Alat yang digunakan yaitu ember, pengki, selang, sikat dan jaring ikan.



(a) Penyapuan Perkerasan

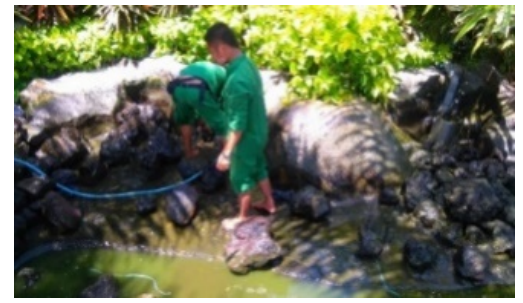

(b) Pembersihan Kolam Ikan

Gambar. 6 Pemeliharaan Kolam Ikan

Bali Tropic Resort and Spa mengaplikasikan tanaman rumput jenis rumput jepang (Zoysia japonica) dan rumput mutiara (Hedyotis corymbosa). Pemangkasan rumput dilakukan setiap satu bulan sekali (Tabel 1). 


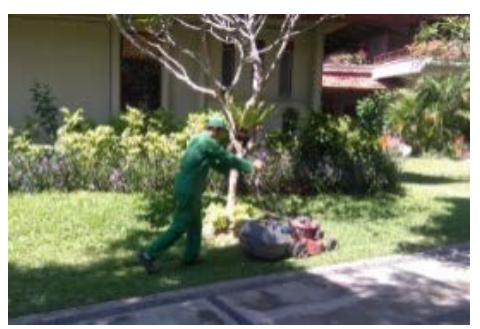

(a)

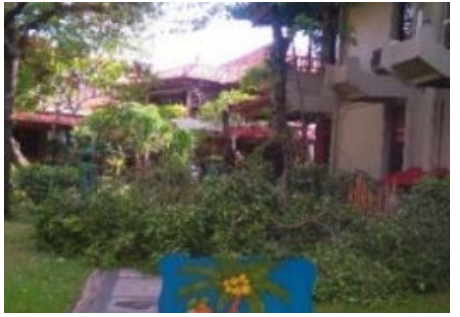

(b)

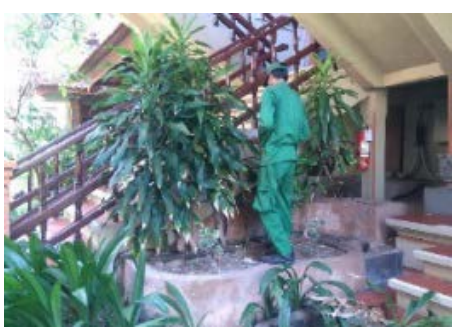

(c)

Gambar. 7 Pemangkasan Tanaman

Pelaksanaan pemangkas rumput dilakukan menggunakan mesin pangkas dorong (Gambar 7a) maupun mesin pangkas gendong. Pemangkasan semak dan perdu dilakukan setiap satu bulan sekali dan alat yang digunakan yaitu gunting pangkas (Gambar 7c). Sampah sisa hasil pemangkasan dimasukan ke dalam plastik sampah dan dibawa ke tempat pembuangan sampah. Sebagian sampah hasil pemangkasan digunakan untuk pembuatan kompos. Pemangkasan pohon biasanya dilakukan dua bulan sekali, tergantung pada musim dan cuaca (Gambar 7b). Pemangkasan pohon ini dilakukan langsung oleh staf gardener, terkecuali jika pemotongan pohon sampai pada akarnya dilakukan langsung oleh tenaga ahli.

Pemupukan pada taman Bali Tropic Resort and Spa dilakukan tiga bulan sekali (Tabel.1). Pupuk yang digunakan yaitu pupuk bokashi dengan dosis dua ton per hektar, pupuk kompos menggunakan dosis kurang lebih 2-4 ton per hektar untuk tanaman semak, perdu dan penutup tanah dengan cara ditaburkan secara merata di atas permukaan tanah atau sering disebut dengan metode broadcast, pupuk NPK dengan dosis 25 gr/pohon dengan cara ditabur disekeliling batang pohon selebar diameter tajuk pohon, kemudian ditutup kembali dengan tanah lalu disiram dengan air agar lebih cepat terlarut, sedangkan dan pupuk urea dengan dosis $10 \mathrm{gr}$ urea dilarutkan kedalam 1,5 L air dan disiram ke permukaan rumput. Pemupukan sebaiknya dilakukan pada musim hujan dan apabila pemupukan tanpa diikuti dengan penyiraman maka akan menyebabkan kerusakan tanaman (Oktaviarni, 2008).

Pengendalian hama dan penyakit di Bali Tropic Resort and Spa dilaksanakan jika terjadi serangan. Metode yang digunakan yaitu dengan cara menyingkirkan tanaman yang terserang hama dan penyakit dan menggunakan metode kimiawi dengan pestisida. Alat yang digunakan yaitu knapsack-sprayer dengan kapasitas $14 \mathrm{~L}$. Insektisida yang digunakan adalah DANE dengan dosis $100 \mathrm{ml}$ setiap $15 \mathrm{~L}$ air (1:150) disemprotkan setiap hari dan fungisida yang digunakan adalah FX dengan dosis $100 \mathrm{ml}$ setiap $40 \mathrm{~L}$ air (1:400) dan disemprotkan setiap hari sebelum akhirnya harus disingkirkan atau dibersihkan.

Pekerjaan penyiraman dilakukan setiap hari (Tabel. 1), tergantung kondisi cuaca (Gambar 18). Kendala yang dialami yaitu kurangnya waktu saat penyiraman dan terpaksa dilakukan pada saat siang hari ini menyebabkan terbakarnya tanaman karena terjadinya penguapan dan sel-sel pada tanaman pun mengkerut karena disiram dalam keadaan panas. Alat yang digunakan yaitu selang $3 / 4$ " dan terkadang dibantu dengan sprinkler.

Pekerjaan pendangiran dilakukan pada siang hari setiap satu bulan sekali (Tabel. 1). Pengendalian gulma pada hamparan taman berumput lebih sering dilakukan bersamaan dengan pemangkasan rumput menggunakan mesin pemotong rumput karena akan lebih cepat dan apabila dilakukan secara manual menghabiskan banyak waktu dan tenaga.

Kegiatan perbanyakan tanaman dilakukan setiap hari. Stok tanaman digunakan untuk kegiatan penyulaman tanaman. Perbanyakan tanaman dilakukan oleh senior gardener. Perabanyakan tanaman dilakukan secara vegetatif dengan cara stek pada bagian batang tanaman (Gambar. 8). Tanaman hasil perbanyakan diletakkan pada satu lokasi yang tidak terlihat oleh wisatawan atau pengunjung resort.

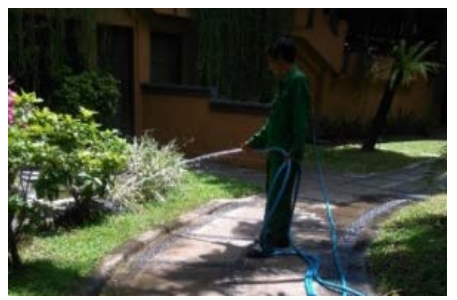

(b) Penyiraman

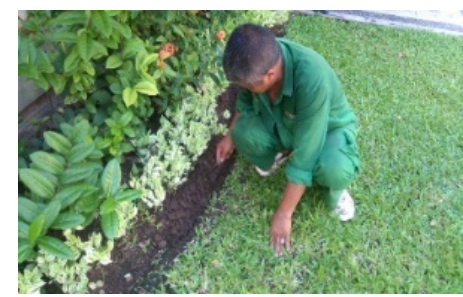

(a) Pedangiran dan Penyiangan Gulma

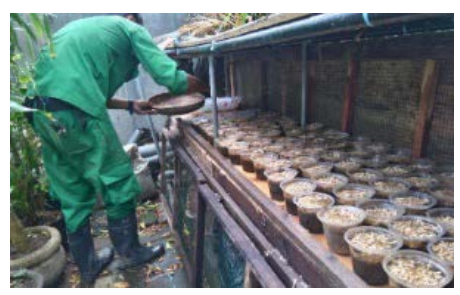

(c). Perbanyakan Tanaman

Gambar. 8 Kegiatan Pemeliharaan Fisik 


\subsubsection{Alat dan Bahan}

Ketersedian alat dan bahan untuk pemeliharaan taman Bali Tropic Resort and Spa dinilai baik. Alat alat yang digunakan dalam pekerjaan meliputi alat tahan lama seperti mesin pemotong rumput gendong, mesin pemotong rumput dororg dan gergaji mesin sedangkan, alat pemeliharaan yang tidak tahan lama seperti sapu dan pengki. Masa efektif alat berbeda-beda tergantung dari jenis alat dan cara perawatannya (Wijayanti,2000). Masa efektif alat kerja pemeliharaan Bali Tropic Resort and Spa dapat dilihat pada Tabel. 3 sebagai berikut:

Tabel. 3 Masa Efektif Alat Kerja Bali Tropic Resort and Spa

\begin{tabular}{|c|c|c|c|}
\hline \multirow{2}{*}{ No } & \multirow{2}{*}{ Alat Kerja } & \multicolumn{2}{|c|}{ Masa Efektif } \\
\hline & & (a) & (b) \\
\hline 1 & Sabit & 6 bulan & 6 bulan \\
\hline 2 & Sapu lidi & 1 bulan & 1 bulan \\
\hline 3 & Sapu daun & 2 bulan & 1 bulan \\
\hline 4 & Pengki & 6 bulan & 6 bulan \\
\hline 5 & Selang air & 2 tahun & - \\
\hline 6 & Gunting pangkas & 1 tahun & 6 bulan \\
\hline 7 & Gunting stek & 1 tahun & 6 bulan \\
\hline 8 & Cangkul & 6 bulan & 6 bulan \\
\hline 9 & Sprinkler & 2 tahun & - \\
\hline 10 & Kored & 3 bulan & 6 bulan \\
\hline 11 & Gergaji manual & 6 bulan & - \\
\hline 12 & Gergaij mesin & 3 tahun & - \\
\hline 13 & Handsprayer & 1 tahun & 3 tahun \\
\hline 14 & Knapsack - sprayer & 4 tahun & - \\
\hline 15 & Mesin pemotong rumput gendong & 2 tahun & 3 tahun \\
\hline 16 & Mesin pemotong rumput dorong & 2 tahun & 3 tahun \\
\hline
\end{tabular}

Keterangan : (a) Pengamatan Lapangan, (b) Wulandari (1992)

Pemeliharaan alat dilakukan secara preventif, meliputi pembersihan dan pergantian oli mesin dan sebagainnya, tujuannya untuk memperpanjang umur alat yang digunakan. Bila terjadi kerusakan yang tidak dapat dihadapi, supervisor gardener melapor kepada housekeeping untuk dibuatkan surat work order yang ditujukan pada engineering untuk diperbaiki. Bahan yang diguanakan yaitu insektisida dan fungisida. Pupuk yang digunakan yaitu pupuk organik dan anorganik. Kegiatan irigasi taman menggunakan air olahan limbah yang berasal dari Lagoon Nusa Dua dan PDAM serta penggunaan bahan bakar premium dan oli untuk mesin pemotong rumput.

\section{Simpulan dan Saran}

\subsection{Simpulan}

Sistem pemeliharaan yang diterapkan yaitu sistem pemeliharaan unit dan karyawan pemeliharaan khusus. Hasil evaluasi pemeliharaan taman pada kawasan Bali Tropic Resort and Spa sudah baik, dilihat dari penilaian oleh pengunjung yang menginap pada resort tersebut.

\subsection{Saran}

Perlu dibuatkan standar pemeliharaan dan jadwal pemeliharaan secara tertulis, monitoring card yang di dalamnya tercantum jenis pekerjaan pemeliharaan. Perlu adanya sistem penghargaan bagi staf gardener, pengoptimalan sumber daya serta menciptakan koordinasi yang harmonis antar pihak untuk meningkatkan efektivitas dan efisiensi kerja serta, pelatihan untuk menambah pengetahuan dan keterampilan kerja.

\section{$5 \quad$ Daftar Pustaka}

Arifin, H.S. and N.H.S. Arifin. 2005. Pemeliharaan Taman (Edisi Revisi). Penebar Swadaya, Jakarta.

Carpenter, P. L., T. D. Walker, and F. O. Lanphear. 1975. Plants In The Landscape. San Fransisco: W. H. Freeman and $\mathrm{Co}$.

Oktaviarni, S.I. 2008. Pengelolaan Pemeliharaan Lanskap di Kawasan Permukiman Sentul City, Bogor, Jawa Barat. Skripsi Program Studi Arsitektur Lanskap, Fakultas Pertanian, Institut Pertanian Bogor (tidak dipublikasikan).

Pudya, A.S. 2000. Pemeliharaan Lanskap Clubhouse di Nirwana Bali Resort. Skripsi Jurusan Budidaya Pertanian, Fakultas Pertanian, Institut Pertanian Bogor (tidak dipublikasikan). 
Sternloff, R. E. dan R. Warren. 1984. Park and Recreation Maintenance Management. John Wiley and Sons Inc. California.

Wijayanti, Agustina. 1992. Pemeliharaan Lanskap Common Area di Kawasan Pariwisata Nusa Dua, Bali, Jurusan Budidaya Pertanian, Institut Pertanian Bogor (tidak dipublikasikan). 